\title{
Online Travel Planning for Families with a Child with a Disability
}

\author{
Mohamed Reda Khomsi ${ }^{(凶)}$, Karl Delorme, and Cyril Martin-Colonna \\ School of Management, Université du Québec À Montréal, \\ Montreal, QC, Canada \\ \{khomsi.mohamed_reda, delorme.karl, \\ martin.cyril\}@uqam.ca
}

\begin{abstract}
Whereas the search for information when starting to plan a trip is generally perceived as enjoyable, families with a disabled child may associate this step with anxiety and stress. This is due to a lack of information and poor consideration of disabled children's needs in most tourist websites, making it difficult for such families to find answers to their questions. In this context, the present research attempts to understand the online travel planning process of families with a child with a disability in order to propose solutions adapted to these families' needs.
\end{abstract}

Keywords: Travel planning $\cdot$ Families with a disabled child $\cdot$ Accessibility

\section{Introduction}

According to the United Nations (UN) [13], 10\% of the world's population lives with a disability, creating life's barriers. Among these barriers, difficulties in accessing cultural, recreational or leisure activities are seen as environmental barriers that prevent a person with a disability from enjoying full citizenship [11]. These difficulties are even more significant when the disability affects a child and when the activity to be done requires travel outside the child's home environment. In that context, the availability of online information becomes an important factor in the travel decision of such families, to the point where some parents may even decide to abandon the idea of taking a trip or engaging in a recreational activity altogether. With this in mind, we wanted to explore the online travel planning process of families with a disabled child as regards the following three questions: 1) What are the main sources of information that families consult when planning a trip or recreational activity?; 2) Which steps, do families follow when seeking to plan and book their trips and recreational activities online?; and 3) Which obstacles do they encounter, online, when doing so?

\section{Research Background}

The issue of web accessibility for people with disabilities is not a recent concern, dating back to the early days of the internet even. For example, from the end of the 1990s, the W3C consortium, launched a project whose mandate is to provide the community of 
web developers and users with a set of standards that allow web technologies to be adapted to the needs of people with disabilities [14]. Over time, these standards, called WCAG - have become a worldwide reference, among others for the development of laws obliging public services to adapt their platforms to offer more accessibility to disabled people. Subsequently, many private companies followed suit and adapted their offer in terms of accessibility accordingly. Within the body of research on web accessibility for people with disabilities, numerous studies have focused on the field of e-commerce, showing that many companies have committed to more inclusive web strategies, as demonstrated by Buzzi et al. [3] and Gladstone et al. [7]. Another strand of this body of research has been focusing on tourism, showing that the information needs of people with disabilities are much greater than those of other categories of travelers [10]. According to Eichhorn and Buhalis [6], the lack of information on the different tourism products are an important barrier to the realization of a travel project. Despite such findings, European destination management organization (DMO) sites have been very slow to adapt their service offer to meet the needs of people with disabilities [9], as shown by a study carried out in 2004.

Despite the increasing amount of research on the accessibility of tourism websites, the issues studied are still quite limited. A search of Google Scholar, ScienceDirect and Erudit databases shows that the vast majority of studies are based on a normative approach, evaluating the degree of compliance of websites with international accessibility standards, particularly those of the WCAG [5]. While these works have certainly contributed to improving the accessibility of tourism websites to people with disabilities, they have paid little attention to the behavioral dimensions of information search on tourism websites. One of the most underexplored topics is online travel planning for people with disabilities. While authors such as Buhalis and Michopoulou [2] have highlighted good web accessibility practices of different tourism websites, none have examined the online search process for users with disabilities in detail. Even more overlooked, as a focus of research, has been the topic families with a child with a disability. Nevertheless, a study conducted by Shikako-Thomas et al. [12] on 87 Canadian families with a disabled child showed that most look to the internet when seeking information for planning leisure activities. When such families fail to find information that reassures them in their plans, many end up abandoning the intended activity altogether, with the risk that this entails for the mental health of all family members.

\section{Theoretical Framework}

Although a number of researchers $[1,4]$ have focused on the use of technology by people with disabilities, to our knowledge there is no research that models travel planning for families with a child with a disability. We thus resorted to, as a starting point, a generic model that describe online travel research and planning developed by Ho et al. [8]. This model identify four dimensions that structure any online tourism information search: 1) The online search for information, consists in analyzing the weight of previous travel experiences, digital platforms used, the keywords used to launch searches, the websites consulted, the comparison of search results and the 
navigation through the different web pages, 2) the information selection process is concerned with the criteria for selecting certain information and not others, the techniques of data conservation and the barriers encountered in a search; 3) The conclusion of the search, concerns the analysis the motivations for ending a search process and the synthesis of the information collected and 4) The analysis of the offline information search, in particular, the exchange and sharing of information with other people and the search for additional information from other sources.

\section{Methodology}

Before explaining the techniques used to collect the data, our first step was to identify our sample by defining the concept of disability. For this, we used the same criteria as those used by the Régie des rentes du Québec (a government agency). The organization defines five types of disabilities (visual, hearing, motor, cognitive and other disabilities) and two levels of severity. In terms of sampling, we targeted 15 families living in two regions, since these two regions, together, account for $45 \%$ of the families receiving family allowances for children with disabilities. To recruit these families, we solicited all the associations that support parents with a child with a disability in Québec and that distributed the call for contributions to their members throughout the spring of 2021 . Once the family was recruited, the data collection was carried out in three different stages. First, the selected participants were asked to complete a short survey about their family, tourism and digital profile. In the second stage, once participants completed the survey, they were asked to take part in a simulation exercise of searching for tourism information for a one-week trip to Paris, France, for the summer of 2021. Once the simulation was over, the participants took part in an interview lasting about $40 \mathrm{~min}$, aimed at deepening their understanding of some of the actions undertaken during the simulation and at asking them about the fourth dimension of the Ho et al. [8] model concerning offline information searches.

\section{Results}

The results obtained so far confirm some of the findings already highlighted in the literature, particularly the complexity of the task of searching for tourism information online. Essentially, even though $67 \%$ of respondents consider the web to facilitate the research process, they consider this task to be tedious and complex, even though their level of computer literacy is quite good and they all have a university education. The second finding that emerged from the research conducted with families concerns the predominance of online booking platforms, regardless of the type of disability of the child. In fact, during the observation phase, $86 \%$ of the participants instinctively initiated their search using by a search engine (Google) and by directly entering the name of these platforms (e.g., Booking, Expedia, Trivago). Despite the fairly significant recourse to OTAs, respondents regret the lack of adapted information and/or travel packages for persons with disabilities. For example, they consider the filters proposed by the different booking platforms to be useful, but regret the fact that they are limited 
only to the physical accessibility of the sites (e.g., shower, lift, ramps). Hence, people suffering from an autism spectrum disorder and/or intellectual disability consider themselves to be discriminatory against. Faced with this situation, some parents of children with such disabilities, after having explored the various options on the OTA sites, will turn to traditional travel agencies to take care of the reservation,

Beyond the usefulness or not of the filters, $83 \%$ of respondents will contact, either before or after booking, the tourism service provider (especially hotels) to get more information about the services offered to people with disabilities. For the participants of our study, the fact of having to contact the hotel, for example, is not to be equated with a lack of trust in the information displayed on the OTA's website but merely as the desire to explain the family's needs properly to avoid misunderstandings.

Finally, the absence of adapted information, which is often the case for tourism activities operated by small businesses, parents will browse the comments left by other users, whether on the OTA site or on sites dedicated to user-generated content, such as Tripadvisor or travel blogs. For the $67 \%$ of people who consult these sites, the purpose of the process is to read the comments of other customers, particularly those with the same limitations. This situation is consistent with the literature that has focused on modelling the planning process for a tourism activity, confirming the importance of peer-to-peer exchange in the decision-making process.

\section{Conclusion and Discussion}

On a theoretical and conceptual level, the results of the research conducted indicate that the online travel planning process of families with a disabled child corresponds with the four dimensions described in the model of Ho et al. [8]. That said, there is one element that appears to be particular among these families, and that is the quality control of the information provided on the websites. In fact, given the low number of comments from users who have the same needs as these families, the latter will contact the providers of tourism services, either before or after booking, to find out more about the service offer in question, or to specify their needs in more detail. On a practical level, we also note that websites' compliance with WACG standards is helpful for people with disabilities who are capable of planning their own travel, but does not meet the needs of people with cognitive impairments. The latter are more discriminated against than other disabled people, as the filters on the vast majority of websites only take into account barriers to mobility. Thus, the results of this kind of study could serve to make tourism companies more aware of these needs, especially considering the evolution of the definition of disability.

For the next steps, we intend to complete the research with the families participating in this study and, at the same time, conduct interviews with producers of tourism information such as OTAs, specialized travel sites, bloggers and organizations that help people with disabilities travel. The objective of this second step is to explore the possibilities of improving the information production process, so as to make it more adapted to families with a disabled child. 


\section{References}

1. Batey G, Waine H (2015) Safe internet access for service users. Learn Disabil Pract 18 (3):16-20. https://doi.org/10.7748/ldp.18.3.16.e1613

2. Buhalis D, Michopoulou E (2012) Information-enabled tourism destination marketing: addressing the accessibility market. Curr Issue Tour 14(2):145-168

3. Buzzi M, Buzzi MC, Leporini B, Akhter F (2009) User trust in ecommerce services: perception via screen reader. In: 2009 international conference on new trends in information and service science, pp 1166-1171. IEEE, Beijing (2009)

4. Dagenais D, Poirier K, Quidot S (2012) Telling the story and understanding the practices: digital inclusion of people with disabilities in Québec. INTECH Québec, City of Québec

5. Domínguez Vila T, Alén González E, Darcy S (2018) Website accessibility in the tourism industry: an analysis of official national tourism organization websites around the world. Disabil Rehabil 40(24):2895-2906

6. Eichhorn V, Buhalis D (2011) Accessibility: a key objective for the tourism industry. In: Buhalis D, Darcy S (eds) Accessible Tourism: Concepts and Issues. Channel View Publications, Bristol, pp 260-273

7. Gladstone K, Rundle C, Alexander T (2002) Accessibility and usability of ecommerce systems. In: Miesenberger K, Klaus J, Zagler W (eds) ICCHP 2002, vol 2398. LNCS. Springer, Heidelberg, pp 11-18. https://doi.org/10.1007/3-540-45491-8_5

8. Ho C-I, Lin M-H, Chen H-M (2012) Web users' behavioral patterns of tourism information search: from online to offline. Tour Manage 33(6):1468-1482

9. Oertel B, Hasse C, Scheermesser M, Thio S1, Feil T (2004) Accessibility of tourism web sites within the European Union. In: Proceedings of the $11^{\text {th }}$ international conference on information and communication technologies in tourism (ENTER 2004), pp 358-368. Springer Verlag, Cairo, Egypt (2004)

10. Pühretmair F, Nussbaum G (2011) Web design, assistive technologies and accessible tourism. In: Buhalis D, Darcy S (eds.) Acessible tourism: concept and issues, pp 274-286. Channel view publication, Bristol (2011)

11. Reichhart F, Myazhiom ACL (2013) Quel tourisme pour les personnes handicapées. Teoros, Revue de recherche en tourisme 32(2):81-85

12. Shikako-Thomas K, Shevell M, Schmitz N, Lach L, Law M, Poulin C (2013) Determinants of participation in leisure activities among adolescents with cerebral palsy. Res Dev Disabil 34(9):2621-2634

13. United Nation. Faits et chiffres sur le handicap. https://www.un.org/development/desa/ disabilities-fr/faits-et-chiffres-sur-lehandicap.html. Accessed 21 Oct 2021

14. W3C. Web Accessibility iniative. WAI early days. https://www.w3.org/WAI/history. Accessed 21 Oct 2021 
Open Access This chapter is licensed under the terms of the Creative Commons Attribution 4.0 International License (http://creativecommons.org/licenses/by/4.0/), which permits use, sharing, adaptation, distribution and reproduction in any medium or format, as long as you give appropriate credit to the original author(s) and the source, provide a link to the Creative Commons license and indicate if changes were made.

The images or other third party material in this chapter are included in the chapter's Creative Commons license, unless indicated otherwise in a credit line to the material. If material is not included in the chapter's Creative Commons license and your intended use is not permitted by statutory regulation or exceeds the permitted use, you will need to obtain permission directly from the copyright holder. 